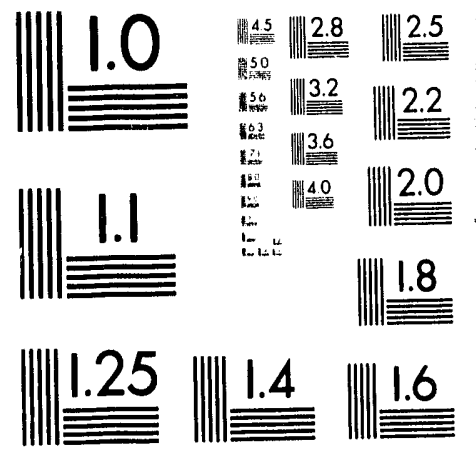



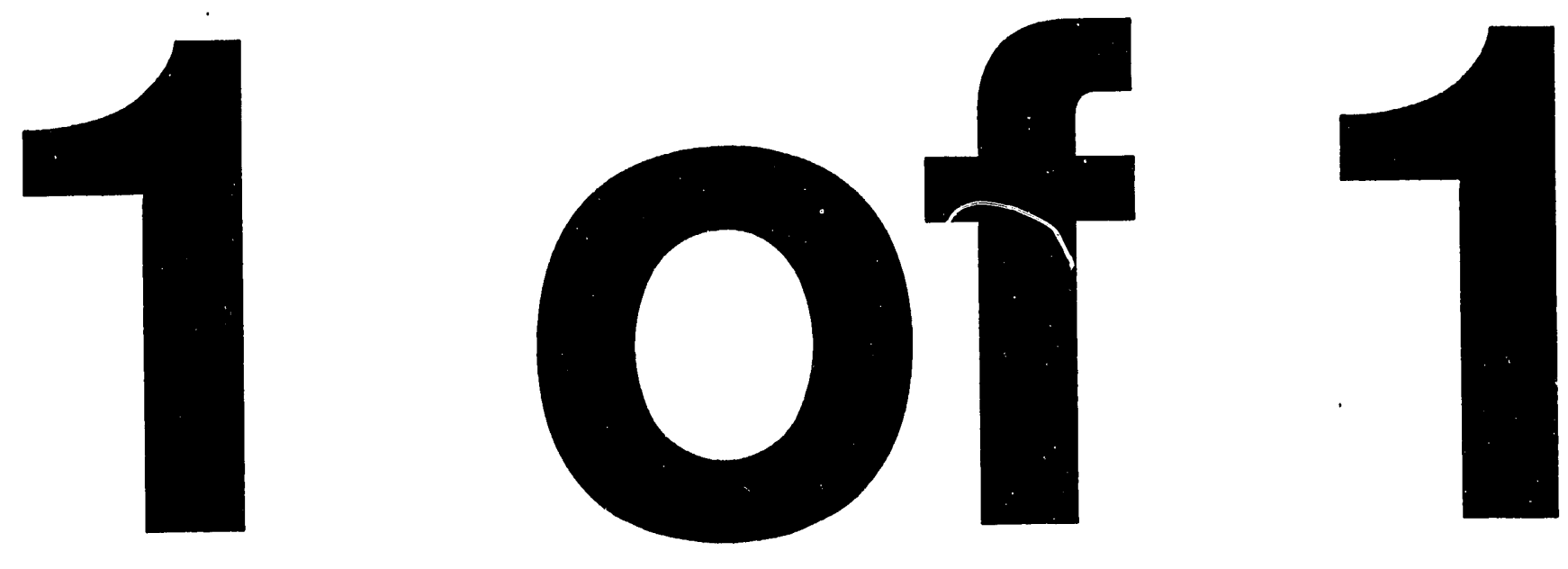


\title{
Project summary
}

\section{Characterization of the Metal-Support Interface in Supported Metal and}

\author{
Supported Metal Complex Catalysts
}

\author{
Bruce C. Gates \\ Center for Catalytic Science and Technology \\ Dept. of Chemical Engineering \\ University of Delaware \\ Newark, DE 19716
}

\section{DISCLAIMER}

This report was prepared as an account of work sponsored by an agency of the United States Government. Neither the United States Government nor any agency thereof, nor any of their employees, makes any warranty, express or implied, or assumes any legal liability or responsibility for the accuracy, completeness, or usefulness of any information, apparatus, product, or process disclosed, or represents that its use would not infringe privately owned rights. Reference herein to any specific commercial product, process, or service by trade name, trademark, manufacturer, or otherwise does not necessarily constitute or imply its endorsement, recommendation, or favoring by the United States Government or any agency thereof. The views and opinions of authors expressed herein do not necessarily state or reflect those of the United States Government or any agency thereof.

\section{MASTER}

The extended X-ray absorption fine structure (EXAFS)

technique has provided the first quantitative


characterizations of metal-suppore interface structures in highly dispersed supported metal catalysts. Thorough data have been obtained for Rh supported on $\gamma-\mathrm{Al}_{2} \mathrm{O}_{3}$ and on $\mathrm{TiO}_{2}$. The EXAFS results for a number of metals on metal oxide supports show metal-oxygen interactions characterized by both short $(2.0-2.2 \AA)$ and long $(2.5-2.8 \AA)$ distances. The structural implications of these distances are still debated.

The objective of the present research is to gain fundamental understanding of the chemistry of metal-metal oxide interfaces by investigating structurally simple and well-defined supported metal catalysts. The characterizations take advantage of the unique capabilities of EXAFs spectroscopy; this technique is used in concert with infrared spectroscopy, temperature-programmed decomposition, and other methods. The strategy is to use organometallic precursors to prepare supported metal complexes with single metal atoms (mononuclear metal complexes) and extremely small supported metal clusters with nearly uniform nuclearities (numbers of metal atoms). Supported metal complexes and small, uniform supported metal clusters offer unprecedented opportunities for precise characterization of the metal structures by EXAFS spectroscopy; the smaller the metal cluster, the larger the fraction of the EXAFS signal that arises from the metalsupport interface and the greater the opportunity for accurate characterization of the interface structure.

$\left[\mathrm{HRe}(\mathrm{CO})_{5}\right], \quad\left[\mathrm{H}_{3} \operatorname{Re}_{3}(\mathrm{CO})_{12}\right], \quad\left[\operatorname{Ir}(\mathrm{CO})_{2}(\mathrm{aCaC})\right], \quad$ and $\left[\operatorname{Ir}_{4}(\mathrm{CO})_{12}\right]$, among others, were chosen to be the precursors. Partially hydroxylated $\mathrm{MgO}, \mathrm{La}_{2} \mathrm{O}_{3}$, zeolite $\mathrm{NaX}$, and zeolite $K L$, among others, were chosen to be the supports, as the chemistry of the metal carbonyls on the basic surfaces of these supports is relatively well understood, being similar to that occurring in basic solutions and allowing synthesis in high yields of supported metal carbonyls including $\operatorname{Re}(\mathrm{CO}) 3$ (OMg) 2 \{HOMg) (where the braces denote groups terminating $\mathrm{MgO}),\left[\mathrm{HIr}_{4}(\mathrm{CO})_{11}\right]^{-}$, and $\left[\operatorname{Ir}_{6}(\mathrm{CO})_{15}\right]^{2-}$, among others, on the surfaces. One of the goals was to form and decarbonylate the metal cluster anions on the supports without changing their nuclearities (numbers of metal atoms ) .

The Mgo support is the one of primary interest, because it offers several advantages for characterization of the samples by $x$-ray absorption spectroscopy. In contrast to the structurally more complex $\gamma-\mathrm{Al}_{2} \mathrm{O}_{3}$ and $\mathrm{TiO}_{2}$, MgO (which has the rock salt structure) exhibits predominantly (100) faces, even in the powder form. Thus the surface of 
Mgo 18 relatively simple and woll deflnod and good chotce for chiracterization of the metal-aupport interface. Furthermore, a both the $\mathrm{o}^{2-}$ and $\mathrm{mg}^{2+}$ lons are present in the sans surface layers, both the $I r-0$ and $I r-M g$ interactions are expected to be well oharacterlzed by the EXAFs (axtended X-ray absorption Ine structure) data. EXAFs ovidence of interactions botween supportad motals and cations of the support has been reported only raraly.

The results of this research provide a prectse charocterization of the metal-support interface. The ExAls data reduction has been carried out with an improved mathod, Including statistical analyois the otructural parameters are beglnging to be reported for the ilrst time with conflaence ilmits determined on the basis of estimates of the nolse in the data.

\section{Importance of the probled}

Extenstve research has been done in the preceding decade in attempte to understand the nature of the mera 1Bupport interrace and to interpret the effecte of supporte on the forformance of supported metal catalysto. This work has demonstrated the role of reductble notal oxide supports $\left(0 . g_{0}, \because \mathrm{O}_{2}\right)$ in forming overlayers $\left(0 . g_{0}\right.$, of $\mathrm{T}\left(\mathrm{O}_{\mathrm{X}}\right)$ that partially cover the motal and may act as catalyst promoters, but the work has falien ahort of provlding insights into the Interactions between metal and typlcal (nonreduclble) metal oxlde supports. The slgnlflouhce of the research summarized nere is that it takes advantage of (1) new synthasis proceduras for the preparation of structuraliy simple and nearly unfform samples and (2) powertul new physloal characterization methods (especially, ExArs spectroscopy) to deterdine the striotures of supported metel spectes, including the atructure of the metal-support interiace. For the flirst time, metal-oxygen bonds have been ldentifled and the coordination of the metal characterlzed quantitatively. Thus, trits work 1s unique in placing the lasues of the metal-support Interactions on a quantitative coundation of otructuril onemistry.

6. Erojiact outrout

A. Hajor reant acoompllshments

Rhentum aubcarbonyls on Mgo

structures formed on the surpace of almost fully dehydrox,plated Ngo by adsorption of [HRe(CO) 3 ] were 
characterized by ExAFS spectroscopy. The rhenium carbonyl initially was molecularly adsorbed, interacting with the Mgo surface as the proton was partially removed by a basic oxygen of the surface; the average $\mathrm{Re}-\mathrm{C}$ and Re-O* coordination numbers (where $0^{*}$ refers to the carbonyl oxygen) are about 5 . There is no EXAFS evidence for interactions of carbonyl oxygen with the surface. The average $R e-C$ and $R e-O^{*}$ distances are 1.94 and $3.13 \dot{A}$, respectively. When adsorbed [HRe $\left.(\mathrm{CO})_{5}\right]$ was heated to $80^{\circ} \mathrm{C}$ in $\mathrm{H}_{2}$, it lost two $\mathrm{CO}$ ligands per Re and formed a subcarbonyl formulated as $\left[\operatorname{Re}(\mathrm{CO})_{3}(\mathrm{HO}-\mathrm{Mg})_{2}(\mathrm{O}-\mathrm{Mg})\right]$. The average $\mathrm{Re}-\mathrm{C}, \mathrm{Re}-\mathrm{O}^{*}$, and Re-O distances are 1.91, 3.12, and $2.13 \dot{A}$, respectively. The Re-O distance is equal, within $+1-$ $0.1 \AA$, to the metal-oxygen distances in the only other wellcharacterized metal subcarbonyls on metal oxides and to the metal-oxygen distances in numerous organometallic complexes with oxygen-containing ligands.

[HRe $\left.(\mathrm{CO})_{5}\right]$ also reacted with the surfaces of partially dehydroxylated (about 55\%) Mgo powder. The initial surface species were again molecularly adsorbed [HRe(CO) $)_{5}$, vhich, upon heating to $80^{\circ} \mathrm{C}$ in $\mathrm{H}_{2}$ or under vacuum, gave rhenium subcarbonyls with three co ligands and three oxygen-containing ligands provided by the Mgo surface. Infrared spectra indicate $C_{3 v}$ symmetry in both structures, with bands at 2011(vs), 1895(vs), and 1862 (sh) $\mathrm{cm}^{-1}$ for rhenium subcarbonyl on the partially dehydroxylated Mgo and at 2017(vs), 1908(vs), and $1867(\mathrm{sh}) \mathrm{cm}^{-1}$ for the rhenium subcarbonyl on the nearly dehydroxylated Mgo. The average bond distances were determined by EXAFS: On the partially dehydroxylated Mgo, the $\mathrm{Re}-\mathrm{C}, \mathrm{Re}-\mathrm{O}^{*}$, and $\mathrm{Re}-\mathrm{O}_{\mathrm{S}}\left(\mathrm{O}_{\mathrm{S}}\right.$ is a surface oxygen) bond lengths were $1.87,3.11$; and $2.13 \dot{A}$, respectively; and on the nevrly dehydroxylated Mgo, they are as stated above. These distancus indicate greater electronic donation (backbonding) from the Re to the co on the partially hydroxylated Mgo than from the Re to the $c 0$ on the almost fully dehydroxylated Mgo surface, suggesting electron transfer from the Mgo to the Re. The Mgo surface is thus modelled as a rigid multidentate electron donor analogous to a molecular ligand. The $x$-ray absorption near edge data confirm a higher electron density on the Re atoms bonded to the oxygens of partially dehydroxylated Mgo than on Re atoms bonded to almost fully dehydroxylated Mgo.

Rhenium subcarbonyls on Mgo powder were also prepared by adsorption and decomposition of $\left[\operatorname{Re}_{2}(\mathrm{CO})_{10}\right]$ and characterized by infrared spectroscopy. The Mgo was treated at various temperatures to give surfaces ranging from those that were virtually fully dehydroxylated to those that were highly hydroxylated; methoxylated surfaces were also prepared by treatment of the Mgo with methanol. The rhenium 
subcarbonyl on the surface has distinctive carbonyl infrared spectra very similar to those of molecular analogues that allow identification of the surface ligands bonded to the rhenium as $\mathrm{O}^{2-}$ on the highly dehydroxylated surface, $\mathrm{OH}^{-}$on the hydroxylated surface, and $\mathrm{CH}_{3} \mathrm{O}^{-}$on the methoxylated surface. A family of surface species is identified, including $\left[\operatorname{Re}(\mathrm{CO})_{3}\{\mathrm{O}-\mathrm{Mg}\}_{3}\right],\left[\operatorname{Re}(\mathrm{CO})_{3}(\mathrm{HOMg}\}_{3}\right],\left[\operatorname{Re}(\mathrm{CO})_{3}\{\mathrm{HO}-\right.$ $\left.\left.\mathrm{Mg}\}_{2} \mid \mathrm{O}-\mathrm{Mg}\right\}\right]$, and $\left[\mathrm{Re}(\mathrm{CO})_{3}\left\{\mathrm{CH}_{3} \mathrm{O}-\mathrm{Mg}\right\}_{3}\right]$.

Iridium clusters on MgO: characterization of the metalsupport interface

$x$-ray absorption spectroscopy was used to characterize the metal-support interface in catalysts consisting of very small Ir clusters of nearly uniform nuclearity on the surface of Mgo powder. $\left[\operatorname{Ir}_{4}(\mathrm{CO})_{12}\right]$ on Mgo was converted in high yield into $\left[\mathrm{HIr}_{4}(\mathrm{CO})_{11}\right]^{-}$and separately into $\left[\operatorname{Ir}_{6}(\mathrm{CO})_{15}\right]^{2-}$. EXAFS data are consistent with the hypothesis that each cluster retained its nuclearity upon decarbonylation. The average Ir-Ir coordination in $\operatorname{Ir}_{4} / \mathrm{MgO}$ is 2.6 neighbors at a distance of $2.72 \dot{A}$, and the structure is modeled as a mixture of tetrahedra and four-atom rafts on Mgo. Another sample was treated in $\mathrm{H}_{2}$ at $350^{\circ} \mathrm{C}$ to give a typical supported metal catalyst having a distribution of Ir clusters averaging $10 \mathrm{~A}$ in diameter. The Ir-support interfaces in $\mathrm{Ir}_{4} / \mathrm{MgO}$ and $\mathrm{Ir}_{6} / \mathrm{MgO}$ are characterized by single Ir-Mg coordinations at 1.6 A and fourfold Ir-O coordinations at $2.6 \AA$; the interface Ir atoms are suggested to be atop $\mathrm{Mg}$ ions in the (100) faces of Mgo.

Characterization of the metal-support interface in supported metal complexes and metal clusters: implications for catalysis

$x$-ray absorption spectra characterizing the metalsupport interface in supported metal complexes and supported metal catalysts have been summarized and evaluated. Transition metal complexes on nonreducible metal oxide supports are bonded with metal-oxygen distances of approximately $2.15 \dot{A}$; the bonding distance is only weakly sensitive to the oxidation state of the metal. Nearly this same metal-oxygen distance is characteristic of the metalsupport interface in metal-oxide-supported metal clusters following reduction in $\mathrm{H}_{2}$ at high temperatures (HTR: $\mathrm{T}$ > $\left.450^{\circ} \mathrm{C}\right)$. The metals at the interface may be polarized sufficiently that they bond with the underlying oxyger much as the metals in mononuclear metal complexes bond with it. 
When the supported metals are treated in $\mathrm{H}_{2}$ at low temperatures (LTR: $\mathrm{T}<350^{\circ} \mathrm{C}$ ) or prepared under He with partially hydroxylated supports, another metal-support oxygen distance is observed, typically 2.5-2.7 $\dot{A}$. This distance is suggested to characterize the metal-oxygen interaction in fully reduced (zerovalent) supported metals. The differences in catalytic performance of low-temperaturereduced (LTR) and high-temperature-reduced (HTR) supported metals are probably related to the differences in electronic properties of the supported metal clusters resulting from the different pretreatment conditions in $\mathrm{H}_{2}$. These differences are inferred to be associated with the abovementioned types of metal-support interactions.

B. Five Recent Publications based on this work

1. J.-R. Chang, L. U. Gron, A. Honji, K. M. Sanchez, and B. C. Gates, "Mononuclear Rhenium Carbonyls on Mgo: Characterization of the Metal-support Interface by Extended X-Ray Absorption Fine Structure spectroscopy," J. Phys. Chem., 1991, 95, 9944.

2. C. J. Papile and B. C. Gates, "Rhenium Subcarbonyls on Magnesium oxide: Identification of the surface oxo and Hydroxo Ligands by Infrared Spectroscopy," Langmuir, $1992,8,74$.

3. A. Honji, L. U. Gron, J.-R. Chang, and B. C. Gates, "Ligand Effects in Supported Metal Carbonyls: X-Ray Absorption spectroscopy of Rhenium Subcarbonyls on Magnesium oxide," submitted to Langmuir.

4. D. C. Koningsberger and B. C. Gates, "Nature of the Metal-Support and Metal-Promoter Interface: Implications of $\mathrm{X}$-Ray Absorption spectroscopy for Catalysis, submitted to Catal. Lett.

5. B. C. Gates and D. C. Koningsberger, "structures of supported Metal Clusters," CHEMTECH, to be published, May, 1992. 

